\title{
Mitochondrial DNA metabolism is coupled with 20S proteasome function via regulation of deoxyribonucleotide homeostasis in Saccharomyces cerevisiae
}

\author{
Xiaowen Wang, Arnav Rana, Liam P. Coyne, Daniel M. Loh, Thuy La and Xin Jie \\ Chen* \\ Department of Biochemistry and Molecular Biology, State University of New York \\ Upstate Medical University, Syracuse, NY 13210, USA
}

Running title: $\quad$ 20S proteasome affects dNTP and mtDNA stability

Key words: $\quad$ mitochondria; mtDNA; mtDNA stability; proteasome;

ribonucleotide reductase; dNTP

*Corresponding author: $\quad$ Tel: (315) 464-8723; Email: chenx@upstate.edu 


\section{SUMMARY}

The synthesis of mitochondrial DNA (mtDNA) is not coupled with cell cycle. Previous studies have shown that the size of deoxyribonucleoside triphosphate (dNTP) pools plays an important role in regulating mtDNA replication and amplification. In yeast, dNTPs are synthesized by the cytosolic ribonucleotide reductase (RNR). It is currently poorly understood as to how RNR activity is regulated in non-dividing or quiescent cells to finely tune mtDNA metabolism to cope with different metabolic states. Here, we show that defect in the $20 \mathrm{~S}$ proteasome drastically destabilizes mtDNA. The mtDNA instability phenotype in 20S proteasome mutants is suppressed by overexpression of $R N R 3$ or by the deletion of $S M L 1$, encoding a minor catalytic subunit and an intrinsic inhibitor of RNR respectively. We found that Sml1 is stabilized in the 20S proteasomal mutants, suggesting that 20S affects mtDNA stability by stabilizing Sml1. Interestingly, defect in the regulatory $19 \mathrm{~S}$ proteasomal function has only subtle effect on mtDNA stability, supporting a role of the $20 \mathrm{~S}$ proteasome in $\mathrm{dNTP}$ homeostasis independent of 19S. Finally, we found that when cells are transitioned from glycolytic to oxidative growth, Sml1 level is reduced in a 20S-dependent manner. In summary, our study establishes a link between cellular proteostasis and mtDNA metabolism through the regulation of dNTP homeostasis. We propose that increased degradation of Sml1 by the 20S proteasome under respiratory conditions provides a mechanism to stimulate dNTP synthesis and promote mtDNA amplification. 


\section{INTRODUCTION}

Mitochondrial DNA (mtDNA) encodes a subset of proteins that directly participate in oxidative phosphorylation (OXPHOS), and ribosomal RNAs and tRNAs that are required for the synthesis of the mtDNA-encoded OXPHOS components inside mitochondria. Loss of mtDNA integrity directly affects cell's energy metabolism. This leads to cell death due to energy deficiency and defects in other mitochondria-associated functions including stress signalling, iron sulfur cluster biosynthesis, cellular proteostasis and programmed cell death. The importance of understanding the mechanism of mtDNA maintenance is underscored by many human diseases that result from mtDNA mutation, deletion, and depletion. These clinical conditions can be caused by direct lesions to mtDNA, due to replicative errors and constant damage by reactive oxygen species. They can also be caused by mutations in nuclear genes that affects mtDNA replication and integrity (WALlaCE 2005; CoPELAND 2008; VAFAI AND MOOTHA 2012; SUOMALAINEN AND BATTERSBY 2017). These genes include those that directly participate in mtDNA replication, such as POLG1 and POLG2 encoding subunits of the mitochondrial DNA polymerase (or Pol $\gamma$ ), and $T W N K$ that encodes the replicative Twinkle helicase.

Mutations in several other genes have been identified that cause mtDNA diseases by affecting the homeostasis of deoxyribonucleotide pools, including $R R M 2 B$ that encodes the p53R2 subunit of ribonucleotide reductase (RNR). RNR is involved in reducing ribonucleoside diphosphates to deoxyribonucleoside diphosphates in the cytosol. The resulting deoxyribonucleotides are then imported into mitochondria, providing precursors for the generation of deoxyribonucleoside triphosphates (dNTPs) that support mtDNA replication. RNR is a tetrameric protein, made up of two dimeric 
subunits: a large catalytic subunit, R1, and the smaller R2 subunit. In mammalian cells, $\mathrm{R} 1$ and R2 move to the nucleus during $\mathrm{S}$ phase to promote dNTP synthesis and DNA replication. $R R M 2 B$ encodes another $\mathrm{R} 2$ protein (or $\mathrm{p} 53 \mathrm{R} 2$ ) and mutations in the gene lead to severe mtDNA depletion and multiple deletions (BOURDON et al. 2007;

TYYNISMAA et al. 2009). It has been shown that Rrm2B resides in the cytosol with a primary function in supporting mtDNA replication (PONTARIN et al. 2008).

Multiple deletions in mtDNA are also associated with diseases affected in several mitochondrial inner membrane (IMM) proteins. For example, mutations in Mpv17 cause mtDNA-depletion diseases (CALvo et al. 2006; SPINAZZOLA et al. 2006). A recent study showed that there is a significant reduction of dNTPs in mitochondria lacking Mpv17 (DALLA Rosa et al. 2016), which further highlights the importance of dNTP homeostatsis for the maintenance of mtDNA integrity. In addition to MPV17, missense mutations in ANT1, involved in ATP/ADP exchange across the IMM, have also been found to cause dominant diseases autosomal dominant Progressive Ophthalmoplegia (adPEO) manifested by deletions and depletion of mtDNA (KAUKONEN et al. 1999; KAUKONEN et al. 2000; THOMPSON et al. 2016). However, the underlying mechanism of mtDNA instability is much less understood. The mutant variants of Ant1 often have moderately reduced nucleotide transport activities (FONTANESI et al. 2004). Recent studies suggested that the dominant pathogenic variants of Ant 1 and its equivalent in yeast, Aac2, clog mitochondrial protein import (Coyne et al., 2021, manuscript under review). This raises the possibility that mtDNA instability may result from a defect in the import of proteins critical for dNTP uptake and/or other mtDNA metabolism processes. 
The synthesis of dNTPs mainly occurs during the $\mathrm{S}$ phase of cell cycle and is normally kept at a very low level in non-dividing or quiescent cells. As mtDNA replication is not coupled with cell cycle, a fundamental but unsolved question is how dNTP synthesis is regulated in non-dividing cells to support mtDNA replication and repair especially when cells need to amplify mtDNA for supporting oxidative metabolism. In this report, we show that reduced $20 \mathrm{~S}$ proteasomal function in yeast greatly compromises mtDNA stability by affecting the level of Sml1, an intrinsic inhibitor of RNR. The data support the idea that the $20 \mathrm{~S}$ proteasome plays an important role in coupling mtDNA replication with respiratory growth through the regulation of RNR activity and dNTP homeostasis. 


\section{MATERIALS AND METHODS}

Growth media and construction of yeast strains. Yeast complete medium (YP) containing $1 \%$ Bacto yeast extract and 2\% Bacto peptone is supplemented with $2 \%$ glucose (YPD) or 2\% galactose (YPGal) or 2\% glycerol (YPGly). Yeast minimal medium (YNBD) contains $0.67 \%$ Difco yeast nitrogen base without amino acids and 2\% glucose. Supplements essential for auxotrophic strains were added to $20 \mu \mathrm{g} / \mathrm{ml}$ for bases and amino acids except for leucine $(30 \mu \mathrm{g} / \mathrm{ml})$. For selecting $\mathrm{G} 418^{\mathrm{R}}$ transformants, geneticin was added to YPD at $300 \mu \mathrm{g} / \mathrm{ml}$. Unless specified, all the yeast strains used in this study are isogenic to M2915-6A or M2915-6alpha. Most null alleles of genes marked by kan were transferred from strains of the yeast knockout collection into the M2915-6A background by PCR amplification and one-step gene replacement. SML1 was disrupted by the insertion of URA3. 3xHA tag was added to the C-terminus of Irc25, Poc4 and Pre9 by integration of a PCR product amplifying from a 3HA-KanMX6 cassette.

Western blot and antibodies. Cell extracts were prepared as previously described (CHEN 2001) and analyzed by SDS-PAGE followed by western blot using antisera against Sml1 (courtesy from Rodney Rothstein laboratory, Columbia University) or HA (Covance\#MMS-101R). Total proteins were stained with REVERT Total Protein Stain (\#926-11011, LI-COR). For western blot, band intensities were quantified by the LI-COR Odyssey Fc Imaging system and normalized against total protein staining or the level of the cytosolic Pgk1 protein.

Petite frequency measurements. All the yeast strains used in this study have the ade2 auxotrophic marker so that petites can be identified as white colonies on YPD. Cells were first 
grown on YPG plates for two days at $30^{\circ} \mathrm{C}$ and then inoculated into $2 \mathrm{ml}$ of YPD broth at $\mathrm{OD}_{600}$ about 0.01 . Cells were grown at 25,30 or $37^{\circ} \mathrm{C}$ for 24 hours. The cultures were then diluted into fresh YPD medium at 1:1000 every 24 hours. At each time point, cells were diluted in water, plated on YPD medium and incubated at $30^{\circ} \mathrm{C}$ for $3-5$ days. Petites were scored as white colonies and totally $200-500$ colonies were counted for each strain.

Multicopy suppressor screen. A $2 \mu \mathrm{m}$-based yeast multicopy genomic library was transformed into the poc4 $\Delta$ mutant. Approximately 5,000 Leu2 ${ }^{+}$transformants were manually picked up, diluted into water in a 96-well microplate, and spotted onto YPD plates. The cells were incubated at $37^{\circ} \mathrm{C}$ for five days. Red colonies were scored. Yeast plasmids were rescued from three red colonies, amplified in Escherichia coli and analyzed by Sanger sequencing. Two clones contain the POC4 gene and the third clone has only the RNR3 gene as a full length ORF in the insert DNA.

Other techniques. Mitochondria were isolated as described by Boldogh and Pon (BOLDOGH AND PON 2007). Briefly, yeast cells were grown in YPGal medium, washed with Tris-SO 4 -DTT, treated with $5 \mathrm{mg}$ zymolyase per gram of yeast to create spheroplasts and then broken with a 40 ml Dounce homogenizer. Mitochondria were collected by differential centrifugation. BN-PAGE was performed using the Life Techonologies NativePAGE ${ }^{\mathrm{TM}}$ Novex ${ }^{\circledR}$ Bis-Tris Gel System as recommended by the manufacturer. Visualization of $\mathrm{F}_{1} \mathrm{~F}_{\mathrm{o}}-\mathrm{ATP}$ synthase complexes by in gel ATPase activity staining was performed according to a previous established procedure (BORNHOVD et al. 2006). 


\section{RESULTS}

\section{Defect in 20S proteasomal function destabilizes mtDNA.}

The proteasome is composed of heteroheptameric $\alpha$-subunit and $\beta$-subunit rings that form the catalytic 20S proteasome, and the 19S regulatory particle (HOCHSTRASSER 1996). Specific chaperones are required for the assembly of the $20 \mathrm{~S}$ proteasome and the $19 \mathrm{~S}$ regulatory particle. The yeast $A A C 2$ gene encodes the major isoform of ATP/ADP translocase on the inner mitochondrial protein. In a previous study, we found that overexpression of POC4 and UMP1, two chaperone proteins for the assembly of the $20 \mathrm{~S}$ proteasome (RAMOS et al. 1998; LE TALLEC et al. 2007; KUSMIERCZYK et al. 2008), suppress cell death induced by $a a c 2^{A 128 P}$ (WANG AND CHEN 2015), equivalent to human ant $1^{A 114 P}$ that causes adPEO manifested by multiple mtDNA deletions. Interestingly, we found that overexpression of these two genes also supress the formation of respiratory deficient petite colonies in a strain expressing $a a c 2^{M 114 P}$ (Fig. 1A). M114P is equivalent to the L98P mutation in human ANT1 that also causes adPEO and multiple mtDNA deletions (NAPOLI et al. 2001). To understand the link between proteasomal function and mtDNA stability, we asked whether disruption of these genes destabilizes mtDNA. Indeed, we found that mtDNA becomes highly unstable in yeast strains disrupted of POC4 and UMP1 when cells were grown in YPD medium at $25^{\circ} \mathrm{C}$ and $30^{\circ} \mathrm{C}$ (Fig. $1 \mathrm{~B}$ and 1C).

To determine whether mtDNA instability results from a general defect in $20 \mathrm{~S}$ proteasomal function, we generated strains lacking IRC25 (or POC3) and BLM10. IRC25 cooperates with POC4 to orchestrate the assembly of the $\alpha 3$ subunit into the $20 \mathrm{~S}$ proteasome. BLM10, the homolog of the human PA28 protein, is an activator of the $20 \mathrm{~S}$ 
proteasome (SCHMIDT et al. 2005). We found that the mutant strains lacking these genes produce petite colonies at both $25^{\circ} \mathrm{C}$ and $30^{\circ} \mathrm{C}$ (Fig. $\left.1 \mathrm{~B}-1 \mathrm{C}\right)$. We also found that disruption of $R P N 4$, encoding a transcriptional factor that activates the expression of proteasomal genes (MANNHAUPT et al. 1999; XIE AND VARSHAVSKY 2001), induces petite production at $25^{\circ} \mathrm{C}$ and $30^{\circ} \mathrm{C}$ (Fig. 1B-1C). The data suggest that the $20 \mathrm{~S}$ proteasomal function is required for maintaining mtDNA stability.

To directly demonstrate a role of the $20 \mathrm{~S}$ proteasome in maintaining mtDNA stability, we disrupted PRE9 that encodes the $\alpha 3$ subunit of 20S. PRE9 is the only nonessential 20S gene, as $\alpha 3$ can be replaced by the $\alpha 4$ subunit to generate an alternative proteasome with an additional copy of $\alpha 4$ (VELICHUTINA et al. 2004; KUSMIERCZYK et al. 2008). As expected, we found that disruption of PRE9 induces petite production (Fig. 1E). The $\alpha 3$ subunit is therefore important for mtDNA stability, which cannot be replaced by the $\alpha 4-\alpha 4$ proteasome. The pre $9 \Delta \operatorname{irc} 25 \Delta$ and pre $9 \Delta$ poc $4 \Delta$ double mutants only slightly increase petite production compared with the pre9 4 single mutant (Fig. 1E), supporting the idea that disruption of $I R C 25$ and POC4 destabilizes mtDNA stability mainly due to the loss of the $\alpha 3$ subunit.

\section{Global proteostasis in the cytosol affects mtDNA stability.}

One possible explanation for reduced mtDNA stability in 20S proteasomal mutants is that low proteasomal activity directly reduces mitochondrial quality by affecting processes such as mitochondrial dynamics, mitophagy and degradation by protein retro-translocation (BRAGOSZEWSKI et al. 2017). mtDNA instability has previously been reported in the blm10 mutant that affects mitochondrial fission (TAR et 
al. 2014). To better understand how proteasomal function affects mtDNA stability, we first examined whether loss of $I R C 25$ and POC4 results in mitochondrial function that secondarily affects mtDNA stability. The $\operatorname{irc} 25 \Delta$ and poc4 $\Delta$ mutants have reduced growth on the non-fermentable glycerol medium, which is consistent with increased mtDNA instability (Fig. 2A). Using blue-native polyacrylamide gel electrophoresis (BNPAGE), we examined the assembly of respiratory supercomplexes. We found that the assembly of the respiratory supercomplexes is little affected in the cells lacking IRC25 and POC4 (Supplemental Fig. 1). Consistent with this, in-gel activity staining showed that the assembly of the dimeric form of the complex $\mathrm{V}\left(\mathrm{V}_{\mathrm{dim}}\right)$, which plays a critical role in morphological control of mitochondrial cristae (PAUMARD et al. 2002), is little affected by the loss of IRC25 and POC4 (Fig. 2B), despite limited release of the free $\mathrm{F}_{1}$ complex due to the loss mtDNA and the membrane $\mathrm{F}_{\mathrm{o}}$ sector of the enzyme. Like in blm10 mutant which increases mitochondrial fission (TAR et al. 2014), we also found that mitochondria are more fragmented in irc 25 $\Delta$ and poc $4 \Delta$ mutants compared with wild type (Fig. 2C).

We subsequently found that global cytosolic proteostasis affects mtDNA stability First, production of petites from all the $20 \mathrm{~S}$ mutants with the exception of $r p n 4 \Delta$ is drastically increased when cells were incubated at $37^{\circ} \mathrm{C}$ (Fig. 1D and 1F). Secondly, disruption of $R P L 6 B$, encoding a cytosolic ribosomal protein, suppressed petite production in $\operatorname{irc} 25 \Delta$ and poc $4 \Delta$ cells (Fig. 2D). Disruption of $R P L 6 B$ only mildly reduces protein synthesis and cell growth (WANG et al. 2008). This appears to be sufficient to improve mtDNA stability in $\operatorname{irc} 25 \Delta$ and poc $4 \Delta$ mutants. The data suggest that loss of mtDNA stability in the $\operatorname{irc} 25 \Delta$ and poc $4 \Delta$ mutants is likely caused by a defect in the degradation of a cytosolic protein. Disruption of RPL6B likely stimulates the 
process by improving cytosolic proteostasis and increasing the availability of proteasome for protein turnover. Thirdly, we found that protein misfolding in the cytosol destabilizes mtDNA (Fig. 2E and 2F). We challenged the cytosolic proteostasis of yeast cells by expressing the human huntingtin proteins from the galactose-inducible GAL10 promoter (MERIIN et al. 2002). We observed an increase in petite production when the aggregationprone Htt103Q variant, which contains an expanded polyglutamine stretch, was expressed. No increased petite production was observed in cells expressing the nonaggregating Htt25Q variants. The data further support the idea that the proteostatic state of the cytosol affects mtDNA stability.

\section{Overexpression of $R N R 3$ and disruption of $S M L 1$ suppress mtDNA loss in 20S mutants.}

To understand how mutations in 20S proteasomal genes reduce mtDNA stability, we performed a multicopy suppressor screen for genes that suppress mtDNA instability in the poc $4 \Delta$ mutant. The poc $4 \Delta$ cells in the ade 2 background form only white colonies at $37^{\circ} \mathrm{C}$ due to the loss of mtDNA. After transformation with a genomic library based on a multicopy vector, we examined $\sim 5,000$ transformants individually for their ability to form red colonies indicative of mtDNA retention when grown at $37^{\circ} \mathrm{C}$ on complete glucose medium (YPD). Three suppressor clones (SOP, for Suppressor of poc4 4 ) were identified (Fig. 3A). Sequence analysis of the suppressor clones showed that the insert DNA in the SOP3 and SOP4 clones contains the POC4 gene, whereas SOP16 contains the $R N R 3$ gene. $R N R 3$ encodes a minor isoform of the large subunit of RNR that catalyzes the rate-limiting step of dNTP biosynthesis. RNR is a tetrameric protein 
complex, consisting of two large (Rnr1 and Rnr3) and two small (Rnr3 and Rnr4) subunits in yeast (Fig. 3B). We found that overexpression of $R N R 1$, encoding the major isoform of the large subunit of RNR, also suppresses the loss of mtDNA from poc4 $\Delta$ cells (not illustrated). The data suggest that defect in 20S proteasomal function may reduce RNR activity and dNTP biosynthesis, which in turn affects mtDNA stability. Supporting this, we found that the $\operatorname{irc} 25 \Delta$ and poc $4 \Delta$ mutants are hypersensitive to hydroxyurea (HU), an inhibitor of RNR (LAMMERS AND FOLLMANN 1984).

RNR is regulated at multiple levels, including transcriptional activation, nuclear translocation, allosteric control and the direct inhibition of enzymatic activity by the Sml1 protein (ZHAO et al. 1998; CHABES et al. 1999; ZHAO et al. 2000; ZHAO et al. 2001) (Fig. 3B). We found that disruption of $S M L 1$ suppresses the hypersensitivity of the $\operatorname{irc} 25 \Delta$ and poc $4 \Delta$ mutants to $\mathrm{HU}$ (Fig. 3C), consistent with the idea that loss of Irc 25 and Poc4 reduces RNR activity. More importantly, we found that deletion of SML1 robustly suppresses the mtDNA instability phenotype in cells disrupted of $I R C 25, P O C 4, R P N 4$, BLM10 and UMP1. Furthermore, mtDNA instability in cells expressing HTT(103Q) is also suppressed by the disruption of $S M L 1$ (Figure 2F). These data strongly suggest that defect in 20S activity and global proteostatic stress destabilize mtDNA by reduced RNR activity.

\section{Stabilization of Sml1 in $20 \mathrm{~S}$ proteasomal mutants.}

Sml1 is a highly unstable protein and is degraded in response to DNA damage which relieves RNR from inhibition and activates dNTP synthesis (ZHAO et al. 1998; CHABES et al. 1999; ZHAO et al. 2000; ZHAO et al. 2001). We hypothesized that the 
mtDNA instability phenotype in 20S proteasomal mutants is caused by reduced turnover of Sml1, which in turn inhibits RNR and dNTP synthesis, and that deletion of SML1 derepresses RNR thereby promoting mtDNA synthesis. Indeed, we found that the steady state levels of Sml1 are drastically increased in cells disrupted of IRC25 and POC4 (see

Fig. 4). The data strongly support the idea that mtDNA instability in the $20 \mathrm{~S}$ proteasomal mutants is mediated by the stabilization of Sml1, which in turn inhibits RNR activity and dNTP biosynthesis.

\section{Loss of 19S proteasomes has subtle effect on Sml1 degradation and mtDNA} stability.

We then examined whether defect in the 19S regulatory complex of the proteasome affects mtDNA stability. Cells with disrupted NAS2, NAS6, RPN14 and TMA17, encoding chaperones required for the assembly of the 19S regulatory particle of the proteasome (ROELOFS et al. 2009; SAEKI et al. 2009; HANSSUM et al. 2014) are viable (Fig. 5A). Surprisingly, we found that disruption of these genes has little effect on mtDNA stability even when cells were grown at $37^{\circ} \mathrm{C}$ (Fig. $5 \mathrm{~B}$ and $5 \mathrm{C}$ ). It is possible that loss of these genes only partially impairs proteasomal function to an extent that is not sufficient to stabilise Sml1 and to affect mtDNA stability. To address this, we disrupted HSM3, encoding another 19S chaperone. The growth of $h s m 3 \Delta$ mutant cells is inhibited at $37^{\circ} \mathrm{C}$ (Fig. 5A), which suggests severe $19 \mathrm{~S}$ proteasome defect. Interestingly, we found that the mutant cells only slightly increase petite production under these conditions. This is consistent with the observation that Sml1 is barely detectable in the $19 \mathrm{~S}$ mutants including $h s m 3 \Delta$ (Fig. 5D and 5E). Taken together, these data suggest that the 19S 
regulatory particle is less critical relative to the $20 \mathrm{~S}$ proteasome for $\mathrm{Sml} 1$ turnover and the maintenance of mtDNA.

\section{Sml1 level is decreased during oxidative growth and in cells with destabilized mtDNA.}

We hypothesized that Sml1-controlled dNTP synthesis may play a role in regulating mtDNA metabolism under conditions of mtDNA amplification and repair. In yeast, mitochondrial respiration is repressed by glucose during glycolytic growth and mtDNA copy number is increased when cells are shifted to oxidative growth. Indeed, we found that Sml1 levels reach the peak in exponentially growing cells (4 hours), begin to decline when cells enter into oxidative growth ( 8 hours), and become barely detectable entering into the stationary phase (Fig. 6A, upper panel). Although Irc25 and Poc4 are also decreased in oxidatively growing cells, the level of Pre9 is maintained (Fig. 6A, lower panel). This suggests the presence of an active $20 \mathrm{~S}$ proteasome in these cells that contributes to Sml1 turnover. Sml1 is slightly stabilized in irc $25 \Delta$ and poc $4 \Delta$ mutants in stationary phase (Fig. 6A, upper panel). We found that Sml1 is further stabilized during oxidative growth in irc25 $\Delta$ pep $4 \Delta$ and poc4 $\Delta$ pep $4 \Delta$ double mutants (Fig. 6B). Pep4 plays an important role in protein turnover in the vacuole. Our data indicate that both $20 \mathrm{~S}$ proteasome and the vacuole participate in the degradation of Sml1 during oxidative growth, with the $20 \mathrm{~S}$ proteasome playing a major role in the process.

In addition to oxidative growth, we found that the steady state levels of Sml1 is significantly reduced in cells disrupted of AFG3, RCA1 and MRPL23 (Fig. 6C and 6D) and in a strain expressing two chromosomally integrated copies of $a a c 2^{M 114 P}$. AFG3 and 
$R C A 1$ encode two subunits of the i-AAA protease on the inner mitochondrial membrane. MRPL23 encodes a subunit of the mitochondrial ribosome. mtDNA is highly unstable in these three mutants. mtDNA is also highly unstable in cells expressing aac $2^{M 114 P}$ (see Fig. 1A). These data support the idea that cells may respond to mtDNA instability by decreasing Sml1 levels as a compensatory mechanism to derepress RNR activity and to promote mtDNA repair and replication. 


\section{DISCUSSION}

The replication of nuclear and mitochondrial DNAs is not obligately coupled (NEWLON AND FANGMAN 1975; SAZER AND SHERWOOD 1990). This is particularly important for quiescent cells in which mtDNA metabolism is required to maintain metabolic capacity in the absence of nuclear DNA replication and cell division. The replication and amplification of mtDNA is highly susceptible to dNTP level fluctuation in yeast (TAYLOR et al. 2005; BRADSHAW et al. 2017; PUDDU et al. 2019), supporting a critical role of the dNTP pools in regulating mtDNA metabolism. However, the bulk of cellular dNTP is synthesized during the $\mathrm{S}$ phase of cell cycle. How mtDNA metabolism is maintained in non-dividing cells is poorly understood. One possibility is that a rather basal level of dNTP synthesizing activity is maintained in the cytosol throughout the cell cycle. This may be necessary to meet the demands for mtDNA replication and repair, without interfering with cell cycle progression that may result from constitutively high levels of dNTP (ChABES AND STILLMAN 2007). The Sml1 protein is an important inhibitor of RNR. Cells lacking Sml1 have higher levels of dNTPs, independent of increase in RNR transcription (ZHAO et al. 1998; TANG et al. 2009). At S phase or after DNA damage, Sml1 is phosphorylated and degraded by the proteasome. This leads to the upregulation of dNTP by RNR that stimulates DNA synthesis and repair (ZHAO AND ROTHSTEIN 2002; ANDRESON et al. 2010). A previous study has observed mtDNA instability in the yeast checkpoint kinase Dun1 mutant that fails to eliminate Sml1 at S phase (ZHAO AND ROTHSTEIN 2002). In this report, we show that defect in the 20S proteasome can directly destabilize mtDNA due to Sml1 overaccumulation. The function of $20 \mathrm{~S}$ proteasome is dynamically controlled under different physiological conditions. 
Out data support a 20S-dependent novel mechanism of RNR regulation and dNTP homeostasis that may be important for mtDNA maintenance and oxidative metabolism in non-dividing cells.

We found that yeast cells disrupted of IRC25, POC4, BLM10, RPN4, UMP1 and PRE9 have drastically destabilized mtDNA. IRC25 and POC4 are involved in the assembly of the $20 \mathrm{~S}$ proteasome. BLM10 is an activator of $20 \mathrm{~S}$ (SCHMIDT et al. 2005). RPN4 encodes a transcriptional factor of proteasomal genes. PRE9 encodes the $\alpha 3$ subunit of $20 \mathrm{~S}$. These observations strongly support a role of the $20 \mathrm{~S}$ proteasome in mtDNA maintenance. Multicopy suppressor screen revealed that overexpression of $R N R 3$ suppresses mtDNA loss from poc $4 \Delta$ cells. More importantly, we found that mtDNA loss from the $20 \mathrm{~S}$ mutants is almost completely suppressed by disruption of SML1. Previous studies have shown mtDNA instability in the blm10 and umpl mutants, which was explained by impaired mitochondrial fission, increased production of reactive oxygen species and defective mismatch repair in mitochondria (MALC et al. 2009; TAR et al. 2014). We found that Sml1 is drastically stabilized in 20S mutants, which would be expected to suppress RNR activity. Based on these data, we conclude that mtDNA instability in the 20S mutants is mainly caused by reduced dNTP synthesis. Our finding provides an explanation for increased sensitivity of blm10 mutants to genotoxins including hydroxyurea (DOHERTY et al. 2012). In all the 20S mutants examined with the exception of $r p n 4 \Delta$, we found that incubation at $37^{\circ} \mathrm{C}$ accelerates mtDNA loss. It has been shown that rpn4 mutant has reduced growth at normal temperature but is indistinguishable from the wild type cells at $37^{\circ} \mathrm{C}$. It has been proposed that compensatory pathways may stimulate proteasomal genes independent of Rpn 4 under the 
heat shock conditions (XIE AND VARSHAVSKY 2001; HAHN et al. 2006), which is likely sufficient to maintain 20 S activity. We found that global proeostatic stress induced by the misfolded human Htt103Q protein also destabilizes mtDNA and this effect is fully suppressed by the disruption of $S M L 1$. Thus, general cellular proteostasis could also modulate dNTP homeostasis and mtDNA stability, possibly by affecting the availability of $20 \mathrm{~S}$ proteasome for the degradation of Smll.

It is interesting to observe that loss of $19 \mathrm{~S}$ function seems to have very subtle effect on mtDNA stability. When the $h s m 3 \Delta$ mutant was incubated at non-permissive temperature to block $19 \mathrm{~S}$ assembly, petite production was only marginally increased. Consistent with this, Sml1 accumulation is only slightly increased relative to what was observed in 20S mutants. This raises the possibility that the $20 \mathrm{~S}$ proteasome may play an important role in the degradation of Sml1 independent of 19S. It has been extensively documented in the literature that the $20 \mathrm{~S}$ proteasome, in contrast to the fully assembled $26 \mathrm{~S}$, is able to degrade unfolded proteins in vitro in an ATP- and ubiquitin-independent fashion (DAVIES 2001; LIU et al. 2003; TSVETKOV et al. 2009). This activity is often facilitated by specific proteasome activators specific to 20S (OPOKU-NSIAH AND GESTWICKI 2018). It has been shown that shown that the N-terminal residues of $\alpha$ subunits play an important role in gating the proteolytic chamber of 20S (BAJOREK et al. 2003; CHOI et al. 2016), and that the substrate entry gate of 20S spontaneously opens to degrade peptides or unfolded proteins. In the absence of the $\alpha 3$ subunit, encoded by PRE9, yeast cells form the $\alpha 4-\alpha 4$ proteasome which has different catalytic activities. Loss of Irc25 and Poc4 required for $\alpha 3$ assembly would also be expected to favor the formation of $\alpha 4-\alpha 4$ proteasomes (VELICHUTINA et al. 2004). Given that the irc 25 and 
poc4 mutants cause overaccumulation of Sml1, the $\alpha 3$ subunit is therefore important for effective degradation of Sml1. It is known that Sml1 is ubiquitylated and its degradation is impaired in 20S mutants (ANDRESON et al. 2010). Future studies are required to learn whether non-ubiquitylated Sml1 is directly subjected to degradation by $20 \mathrm{~S}$ independent of 19S and substrate ubiquitylation.

It is intriguing to observe that Sml1 is reduced to barely detectable levels when yeast cells enter stationary phase or quiescent state. This could be physiologically relevant. At the post-exponential growth phase, cell division is slowed down and oxidative metabolism is derepressed. Cells enter into a metabolic mode where mitochondrial mass is expanded and mtDNA copy number is increased. Interestingly, yeast cells at the stationary phase have been shown to increase proteasomal activity and to have increased release of 20S from the 26S proteasome (FUJIMURO et al. 1998; BAJOREK et al. 2003). We showed that the levels of 20S subunits such as Pre9 is maintained in the stationary phase. Both 20S activity and vacuole-mediated proteolytic activity are required for the degradation of Sml1 in stationary phase. Based on these data, we speculate that RNR activity is kept very low under normal growth conditions in non-S phase cells because of Sml1 inhibition. When transitioning to oxidative growth, increased degradation of Sml1 derepresses RNR and stimulates dNTP synthesis which in turn promotes mtDNA amplification and oxidative metabolism. Thus, the $20 \mathrm{~S}$ proteasome serves as a novel regulatory loop to fine-tuning dNTP levels, allowing mtDNA replication when cells are switched to oxidative metabolism. This regulatory loop is vulnerable as demonstrated by the drastic destabilization of mtDNA in cells with $20 \mathrm{~S}$ deficiency. Interestingly, we also observed that Sml1 is reduced in cells with destabilized 
mtDNA. It is known that mitochondrial damage activates proteasomal function in the cytosol (WrOBEL et al. 2015) and is often marked by the release of 20S from the 26S proteasome (LIVNAT-LEVANON et al. 2014). In this regard, it is possible that proteasomebased Sml1 degradation serves as a stress response that may retrogradely stimulate mtDNA metabolism by derepressing RNR activity.

Coupling dNTP homeostasis with proteostasis is not unprecedented. In Caulobacter crescentus, increased proteostatic stress reduces the availability of the Lon protease that normally degrades the transcriptional factor CcrM involved in dNTP production (ZEINERT et al. 2020). As such, dNTP levels are increased to maintain replication capacity when midfolded proteins burden increases. In light of the current study, yeast cells appear to couple proteostasis with dNTP homeostasis to regulate mtDNA metabolism independent of cell cycle. In mammalian cells, the p53R2 subunit seems to play a key role in mtDNA maintenance (PONTARIN et al. 2008). In light of the current study, it would be interesting to find out in the future whether activity of the $\mathrm{R} 1 / \mathrm{p} 53 \mathrm{R} 2$ enzyme is also regulated by the proteostatic status of the cell. 


\section{REFERENCES}

Andreson, B. L., A. Gupta, B. P. Georgieva and R. Rothstein, 2010 The ribonucleotide reductase inhibitor, Sml1, is sequentially phosphorylated, ubiquitylated and degraded in response to DNA damage. Nucleic Acids Res 38: 6490-6501.

Bajorek, M., D. Finley and M. H. Glickman, 2003 Proteasome disassembly and downregulation is correlated with viability during stationary phase. Curr Biol 13: 1140-1144.

Boldogh, I. R., and L. A. Pon, 2007 Purification and subfractionation of mitochondria from the yeast Saccharomyces cerevisiae. Methods Cell Biol 80: 45-64.

Bornhovd, C., F. Vogel, W. Neupert and A. S. Reichert, 2006 Mitochondrial membrane potential is dependent on the oligomeric state of F1F0-ATP synthase supracomplexes. J Biol Chem 281: 13990-13998.

Bourdon, A., L. Minai, V. Serre, J. P. Jais, E. Sarzi et al., 2007 Mutation of RRM2B, encoding p53-controlled ribonucleotide reductase (p53R2), causes severe mitochondrial DNA depletion. Nat Genet 39: 776-780.

Bradshaw, E., M. Yoshida and F. Ling, 2017 Regulation of Small Mitochondrial DNA Replicative Advantage by Ribonucleotide Reductase in Saccharomyces cerevisiae. G3 (Bethesda) 7: 3083-3090.

Bragoszewski, P., M. Turek and A. Chacinska, 2017 Control of mitochondrial biogenesis and function by the ubiquitin-proteasome system. Open Biol 7.

Calvo, S., M. Jain, X. Xie, S. A. Sheth, B. Chang et al., 2006 Systematic identification of human mitochondrial disease genes through integrative genomics. Nat Genet 38: 576-582. 
Chabes, A., V. Domkin and L. Thelander, 1999 Yeast Sml1, a protein inhibitor of ribonucleotide reductase. J Biol Chem 274: 36679-36683.

Chabes, A., and B. Stillman, 2007 Constitutively high dNTP concentration inhibits cell cycle progression and the DNA damage checkpoint in yeast Saccharomyces cerevisiae. Proc Natl Acad Sci U S A 104: 1183-1188.

Chen, X. J., 2001 Activity of the Kluyveromyces lactis Pdr5 multidrug transporter is modulated by the Sit4 protein phosphatase. J Bacteriol 183: 3939-3948.

Choi, W. H., S. A. de Poot, J. H. Lee, J. H. Kim, D. H. Han et al., 2016 Open-gate mutants of the mammalian proteasome show enhanced ubiquitin-conjugate degradation. Nat Commun 7: 10963.

Copeland, W. C., 2008 Inherited mitochondrial diseases of DNA replication. Annu Rev Med 59: 131-146.

Dalla Rosa, I., Y. Camara, R. Durigon, C. F. Moss, S. Vidoni et al., 2016 MPV17 Loss Causes Deoxynucleotide Insufficiency and Slow DNA Replication in Mitochondria. PLoS Genet 12: e1005779.

Davies, K. J., 2001 Degradation of oxidized proteins by the 20 S proteasome. Biochimie 83: 301-310.

Doherty, K. M., L. D. Pride, J. Lukose, B. E. Snydsman, R. Charles et al., 2012 Loss of a 20S proteasome activator in Saccharomyces cerevisiae downregulates genes important for genomic integrity, increases DNA damage, and selectively sensitizes cells to agents with diverse mechanisms of action. G3 (Bethesda) 2: 943-959. 
Fontanesi, F., L. Palmieri, P. Scarcia, T. Lodi, C. Donnini et al., 2004 Mutations in $A A C 2$, equivalent to human adPEO-associated ANT1 mutations, lead to defective oxidative phosphorylation in Saccharomyces cerevisiae and affect mitochondrial DNA stability. Hum Mol Genet 13: 923-934.

Fujimuro, M., H. Takada, Y. Saeki, A. Toh-e, K. Tanaka et al., 1998 Growth-dependent change of the $26 \mathrm{~S}$ proteasome in budding yeast. Biochem Biophys Res Commun 251: 818-823.

Hahn, J. S., D. W. Neef and D. J. Thiele, 2006 A stress regulatory network for coordinated activation of proteasome expression mediated by yeast heat shock transcription factor. Mol Microbiol 60: 240-251.

Hanssum, A., Z. Zhong, A. Rousseau, A. Krzyzosiak, A. Sigurdardottir et al., 2014 An inducible chaperone adapts proteasome assembly to stress. Mol Cell 55: 566-577.

Hochstrasser, M., 1996 Ubiquitin-dependent protein degradation. Annu Rev Genet 30: $405-439$.

Kaukonen, J., J. K. Juselius, V. Tiranti, A. Kyttala, M. Zeviani et al., 2000 Role of adenine nucleotide translocator 1 in mtDNA maintenance. Science 289: 782-785.

Kaukonen, J., M. Zeviani, G. P. Comi, M. G. Piscaglia, L. Peltonen et al., 1999 A third locus predisposing to multiple deletions of mtDNA in autosomal dominant progressive external ophthalmoplegia. Am J Hum Genet 65: 256-261.

Kusmierczyk, A. R., M. J. Kunjappu, M. Funakoshi and M. Hochstrasser, 2008 A multimeric assembly factor controls the formation of alternative $20 \mathrm{~S}$ proteasomes. Nat Struct Mol Biol 15: 237-244. 
Lammers, M., and H. Follmann, 1984 Deoxyribonucleotide biosynthesis in yeast (Saccharomyces cerevisiae). A ribonucleotide reductase system of sufficient activity for DNA synthesis. Eur J Biochem 140: 281-287.

Le Tallec, B., M. B. Barrault, R. Courbeyrette, R. Guerois, M. C. Marsolier-Kergoat et al., $200720 \mathrm{~S}$ proteasome assembly is orchestrated by two distinct pairs of chaperones in yeast and in mammals. Mol Cell 27: 660-674.

Liu, C. W., M. J. Corboy, G. N. DeMartino and P. J. Thomas, 2003 Endoproteolytic activity of the proteasome. Science 299: 408-411.

Livnat-Levanon, N., E. Kevei, O. Kleifeld, D. Krutauz, A. Segref et al., 2014 Reversible 26S proteasome disassembly upon mitochondrial stress. Cell Rep 7: 1371-1380.

Malc, E., P. Dzierzbicki, A. Kaniak, A. Skoneczna and Z. Ciesla, 2009 Inactivation of the 20S proteasome maturase, Ump1p, leads to the instability of mtDNA in Saccharomyces cerevisiae. Mutat Res 669: 95-103.

Mannhaupt, G., R. Schnall, V. Karpov, I. Vetter and H. Feldmann, 1999 Rpn4p acts as a transcription factor by binding to PACE, a nonamer box found upstream of $26 \mathrm{~S}$ proteasomal and other genes in yeast. FEBS Lett 450: 27-34.

Meriin, A. B., X. Zhang, X. He, G. P. Newnam, Y. O. Chernoff et al., 2002 Huntington toxicity in yeast model depends on polyglutamine aggregation mediated by a prion-like protein Rnq1. J Cell Biol 157: 997-1004.

Napoli, L., A. Bordoni, M. Zeviani, G. M. Hadjigeorgiou, M. Sciacco et al., 2001 A novel missense adenine nucleotide translocator-1 gene mutation in a Greek adPEO family. Neurology 57: 2295-2298. 
Newlon, C. S., and W. L. Fangman, 1975 Mitochondrial DNA synthesis in cell cycle mutants of Saccharomyces cerevisiae. Cell 5: 423-428.

Opoku-Nsiah, K. A., and J. E. Gestwicki, 2018 Aim for the core: suitability of the ubiquitin-independent 20S proteasome as a drug target in neurodegeneration. Transl Res 198: 48-57.

Paumard, P., J. Vaillier, B. Coulary, J. Schaeffer, V. Soubannier et al., 2002 The ATP synthase is involved in generating mitochondrial cristae morphology. EMBO J 21: 221-230.

Pontarin, G., A. Fijolek, P. Pizzo, P. Ferraro, C. Rampazzo et al., 2008 Ribonucleotide reduction is a cytosolic process in mammalian cells independently of DNA damage. Proc Natl Acad Sci U S A 105: 17801-17806.

Puddu, F., M. Herzog, A. Selivanova, S. Wang, J. Zhu et al., 2019 Genome architecture and stability in the Saccharomyces cerevisiae knockout collection. Nature 573: 416-420.

Ramos, P. C., J. Hockendorff, E. S. Johnson, A. Varshavsky and R. J. Dohmen, 1998 Ump1p is required for proper maturation of the $20 \mathrm{~S}$ proteasome and becomes its substrate upon completion of the assembly. Cell 92: 489-499.

Roelofs, J., S. Park, W. Haas, G. Tian, F. E. McAllister et al., 2009 Chaperone-mediated pathway of proteasome regulatory particle assembly. Nature 459: 861-865.

Saeki, Y., E. A. Toh, T. Kudo, H. Kawamura and K. Tanaka, 2009 Multiple proteasomeinteracting proteins assist the assembly of the yeast 19S regulatory particle. Cell 137: $900-913$. 
Sazer, S., and S. W. Sherwood, 1990 Mitochondrial growth and DNA synthesis occur in the absence of nuclear DNA replication in fission yeast. J Cell Sci 97 ( Pt 3): 509516.

Schmidt, M., W. Haas, B. Crosas, P. G. Santamaria, S. P. Gygi et al., 2005 The HEAT repeat protein Blm10 regulates the yeast proteasome by capping the core particle. Nat Struct Mol Biol 12: 294-303.

Spinazzola, A., C. Viscomi, E. Fernandez-Vizarra, F. Carrara, P. D'Adamo et al., 2006 MPV17 encodes an inner mitochondrial membrane protein and is mutated in infantile hepatic mitochondrial DNA depletion. Nat Genet 38: 570-575.

Suomalainen, A., and B. J. Battersby, 2017 Mitochondrial diseases: the contribution of organelle stress responses to pathology. Nat Rev Mol Cell Biol.

Tang, H. M., K. L. Siu, C. M. Wong and D. Y. Jin, 2009 Loss of yeast peroxiredoxin Tsa1p induces genome instability through activation of the DNA damage checkpoint and elevation of dNTP levels. PLoS Genet 5: e1000697.

Tar, K., T. Dange, C. Yang, Y. Yao, A. L. Bulteau et al., 2014 Proteasomes associated with the Blm10 activator protein antagonize mitochondrial fission through degradation of the fission protein Dnm1. J Biol Chem 289: 12145-12156.

Taylor, S. D., H. Zhang, J. S. Eaton, M. S. Rodeheffer, M. A. Lebedeva et al., 2005 The conserved Mec1/Rad53 nuclear checkpoint pathway regulates mitochondrial DNA copy number in Saccharomyces cerevisiae. Mol Biol Cell 16: 3010-3018.

Thompson, K., H. Majd, C. Dallabona, K. Reinson, M. S. King et al., 2016 Recurrent De Novo Dominant Mutations in SLC25A4 Cause Severe Early-Onset Mitochondrial 
Disease and Loss of Mitochondrial DNA Copy Number. Am J Hum Genet 99: 1405.

Tsvetkov, P., N. Reuven, C. Prives and Y. Shaul, 2009 Susceptibility of p53 unstructured $\mathrm{N}$ terminus to $20 \mathrm{~S}$ proteasomal degradation programs the stress response. $\mathrm{J}$ Biol Chem 284: 26234-26242.

Tyynismaa, H., E. Ylikallio, M. Patel, M. J. Molnar, R. G. Haller et al., 2009 A heterozygous truncating mutation in RRM2B causes autosomal-dominant progressive external ophthalmoplegia with multiple mtDNA deletions. Am J Hum Genet 85: 290-295.

Vafai, S. B., and V. K. Mootha, 2012 Mitochondrial disorders as windows into an ancient organelle. Nature 491: 374-383.

Velichutina, I., P. L. Connerly, C. S. Arendt, X. Li and M. Hochstrasser, 2004 Plasticity in eucaryotic $20 \mathrm{~S}$ proteasome ring assembly revealed by a subunit deletion in yeast. EMBO J 23: 500-510.

Wallace, D. C., 2005 A mitochondrial paradigm of metabolic and degenerative diseases, aging, and cancer: a dawn for evolutionary medicine. Annu Rev Genet 39: 359407.

Wang, X., and X. J. Chen, 2015 A cytosolic network suppressing mitochondria-mediated proteostatic stress and cell death. Nature 524: 481-484.

Wang, X. W., X. M. Zuo, B. Kucejova and X. J. Chen, 2008 Reduced cytosolic protein synthesis suppresses mitochondrial degeneration. Nature Cell Biology 10: 10901097. 
Wrobel, L., U. Topf, P. Bragoszewski, S. Wiese, M. E. Sztolsztener et al., 2015

Mistargeted mitochondrial proteins activate a proteostatic response in the cytosol. Nature 524: 485-488.

Xie, Y., and A. Varshavsky, 2001 RPN4 is a ligand, substrate, and transcriptional regulator of the $26 \mathrm{~S}$ proteasome: a negative feedback circuit. Proc Natl Acad Sci U S A 98: 3056-3061.

Zeinert, R. D., H. Baniasadi, B. P. Tu and P. Chien, 2020 The Lon Protease Links Nucleotide Metabolism with Proteotoxic Stress. Mol Cell 79: 758-767 e756.

Zhao, X., A. Chabes, V. Domkin, L. Thelander and R. Rothstein, 2001 The ribonucleotide reductase inhibitor Sml1 is a new target of the Mec1/Rad53 kinase cascade during growth and in response to DNA damage. EMBO J 20: 3544-3553.

Zhao, X., B. Georgieva, A. Chabes, V. Domkin, J. H. Ippel et al., 2000 Mutational and structural analyses of the ribonucleotide reductase inhibitor Sml1 define its Rnr1 interaction domain whose inactivation allows suppression of mec1 and rad53 lethality. Mol Cell Biol 20: 9076-9083.

Zhao, X., E. G. Muller and R. Rothstein, 1998 A suppressor of two essential checkpoint genes identifies a novel protein that negatively affects dNTP pools. Mol Cell 2: 329-340.

Zhao, X., and R. Rothstein, 2002 The Dun1 checkpoint kinase phosphorylates and regulates the ribonucleotide reductase inhibitor Sml1. Proc Natl Acad Sci U S A 99: 3746-3751. 
ACKNOWLEDGEMENTS: We thanks Rodney Rothstein for providing the anti-Sml1 antibody and Brooke Hamling for help in yeast strain construction. This work was supported by the NIH grants AG061204 and AG063499 to X.J.C., and F30AG-060702 to L.P.C.. 
Table 1. Yeast strains used in the study.

\begin{tabular}{|c|c|c|}
\hline Strain & Genotype & Sources \\
\hline M2915-6A & MATa, ade2, ura3, leu2 & This laboratory \\
\hline M2915-6alpha & MAT $\alpha$, ade 2, ura3, leu2 & This laboratory \\
\hline CY5002 & as M2915-6alpha, but irc25 $:: k a n$ & This study \\
\hline CY4990 & as M2915-6alpha, but poc4 $\because: k a n$ & This study \\
\hline CY5004 & as M2915-6alpha, but $r p n 4 \Delta:: k a n$ & This study \\
\hline CY5075 & as M2915-6alpha, but blm10 & This study \\
\hline CY4495 & as M2915-6A, but ump1 $\because:$ kan & This study \\
\hline CY5940 & as M2915-6A, but pre94::kan & This study \\
\hline CY5806 & M2915-6A background, but afg3 $\triangle: \because U R A 3$ & This study \\
\hline CY5808 & M2915-6A background, but rcal $\triangle:: U R A 3$ & This study \\
\hline CY5549 & M2915-6A background, but $m r p l 23 \triangle \because U R A 3$ & This study \\
\hline CY6077 & M2915-6A background, but sml1 $\triangle:: U R A 3$ & This study \\
\hline CY5863 & M2915-6A background, but $\operatorname{irc} 25 \Delta:: k a n$, sml1 $\triangle:: U R A 3$ & This study \\
\hline CY5864 & M2915-6A background, but poc4A::kan, smll $\Delta:: U R A 3$ & This study \\
\hline CY5866 & M2915-6A background, but rpn44A::kan, sml1 $\Delta:: U R A 3$ & This study \\
\hline CY5868 & M2915-6A background, but blm10 $:: k a n$, sml1 $\triangle: \because U R A 3$ & This study \\
\hline CY5869 & M2915-6A background, but ump1 $\triangle:: k a n$, sml1 $\triangle:: U R A 3$ & This study \\
\hline CY5929 & as M2915-6A, but nas2 $\Delta:: k a n$ & This study \\
\hline CY5931 & as M2915-6A, but nas6 $\because: k a n$ & This study \\
\hline CY5934 & as M2915-6A, but hsm3 $\Delta:: k a n$ & This study \\
\hline CY5935 & as M2915-6A, but rpn144::kan & This study \\
\hline CY5937 & as M2915-6A, but tma17 $\because: k a n$ & This study \\
\hline CY6068 & as M2915-6A, but pep4 $\Delta:: k a n$ & This study \\
\hline CY5953 & M2915-6A background, but irc25 $:: k a n$, pre9 $9:: k a n$ & This study \\
\hline CY5955 & M2915-6A background, but poc4 $4:: k a n$, pre $9 \Delta:: k a n$ & This study \\
\hline CY6199 & 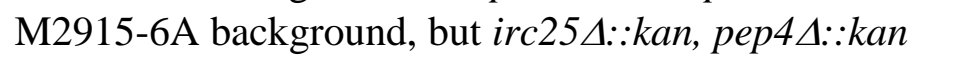 & This study \\
\hline CY6189 & M2915-6A background, poc4 $4:$ kan, pep4 $\because: k a n$ & This study \\
\hline W303-1B/A & MATa, ade2, trp1, his3, leu2, ura3 & R. Rothstein \\
\hline CS1460-2D & $\begin{array}{l}\text { as W303-1B/A, but } \operatorname{trp} 1 \Delta: \because a a c 2^{M 114 P}-U R A 3 \text {, } \\
\text { lys } 2 \Delta:: a a c 2^{M 114 P}-k a n\end{array}$ & Wang et al., 2008 \\
\hline CY5941 & as M2915-6A, but IRC25-3HA-kan & This study \\
\hline CY5943 & as M2915-6A, but POC4-3HA-kan & This study \\
\hline CY5951 & as M2915-6A, but PRE9-3HA-kan & This study \\
\hline
\end{tabular}


A
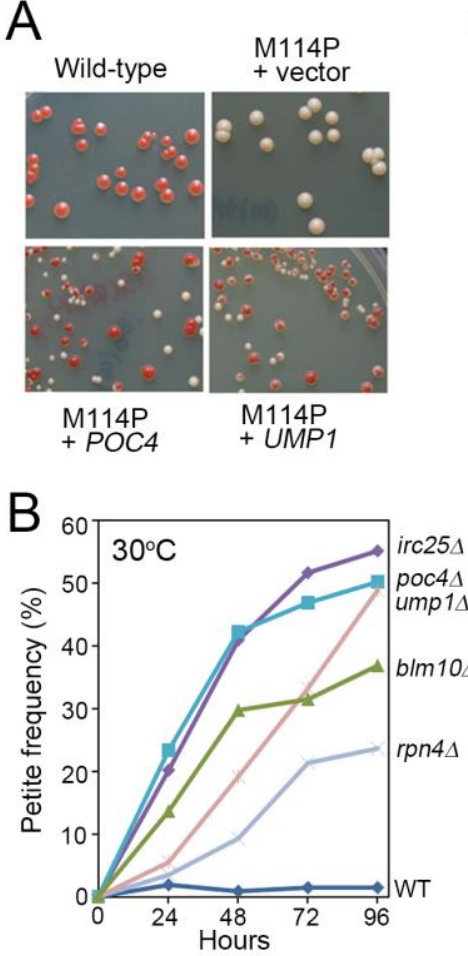

C
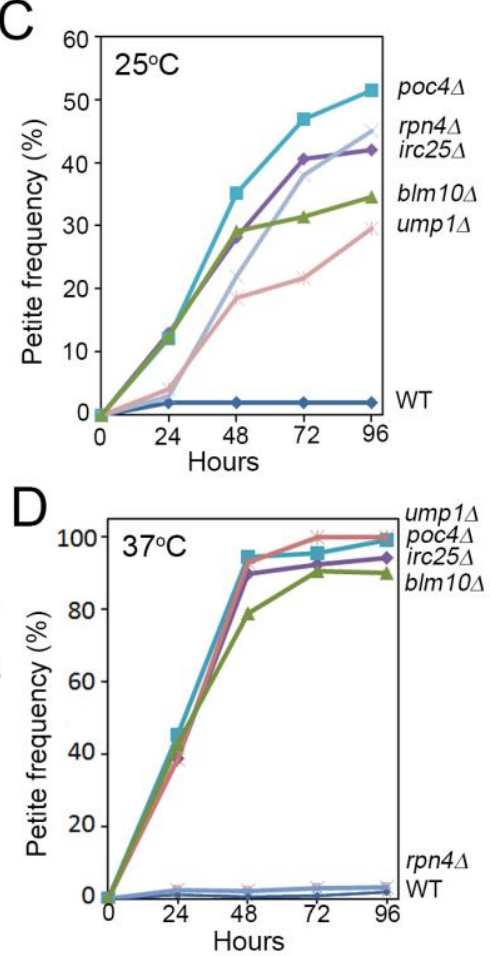
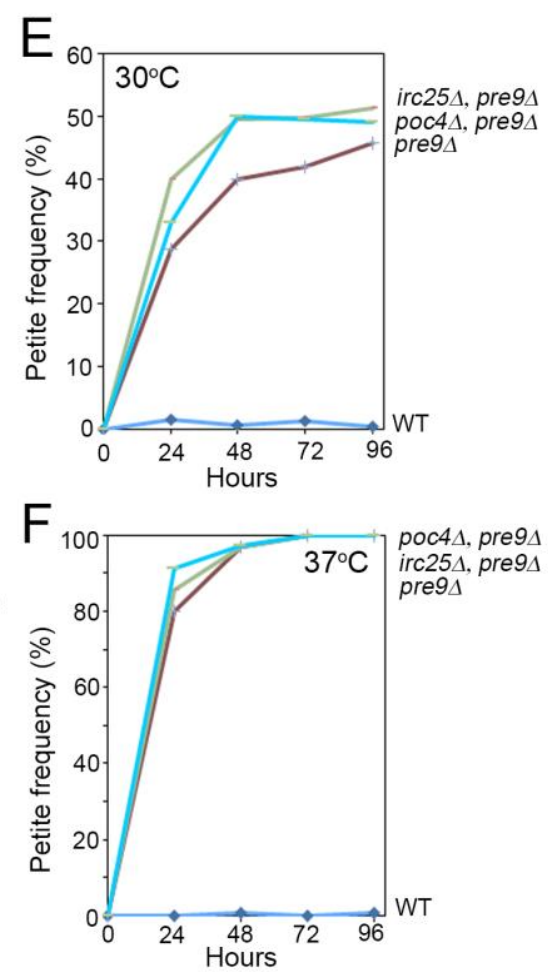

Figure 1

Figure 1. Overexpression and disruption of $20 \mathrm{~S}$ proteasomal genes affect mtDNA stability. (A) Overexpression of POC4 and UMP1 from a multicopy vector suppresses the production of petite (white) colonies in cells expressing the chromosomally integrated $\operatorname{aac} 2^{M 114 P}(\mathrm{M} 114 \mathrm{P})$ allele. The strain CS1460-2D was transformed with the plasmids expressing POC4 and UMP1. $\mathrm{Leu}^{+}$transformants were diluted in water and plated on YPD medium to allow colony formation at $30^{\circ} \mathrm{C}$ for $4-5$ days. (B) - (F) Petite frequency in $20 \mathrm{~S}$ proteasomal mutants grown in liquid YPD medium at temperatures as indicated. 


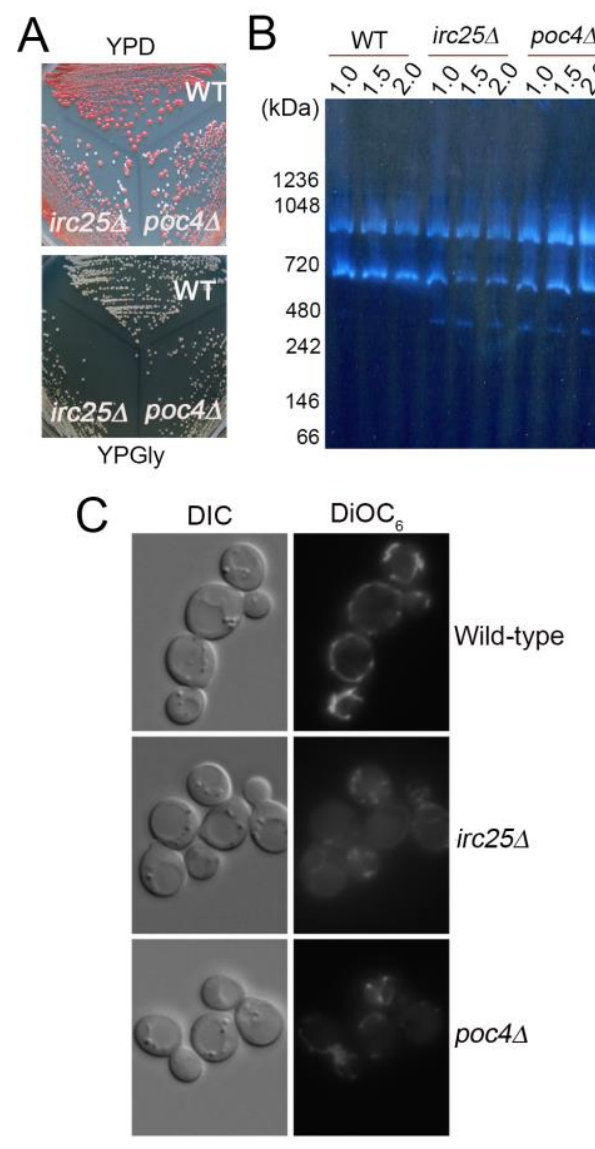

Figure 2
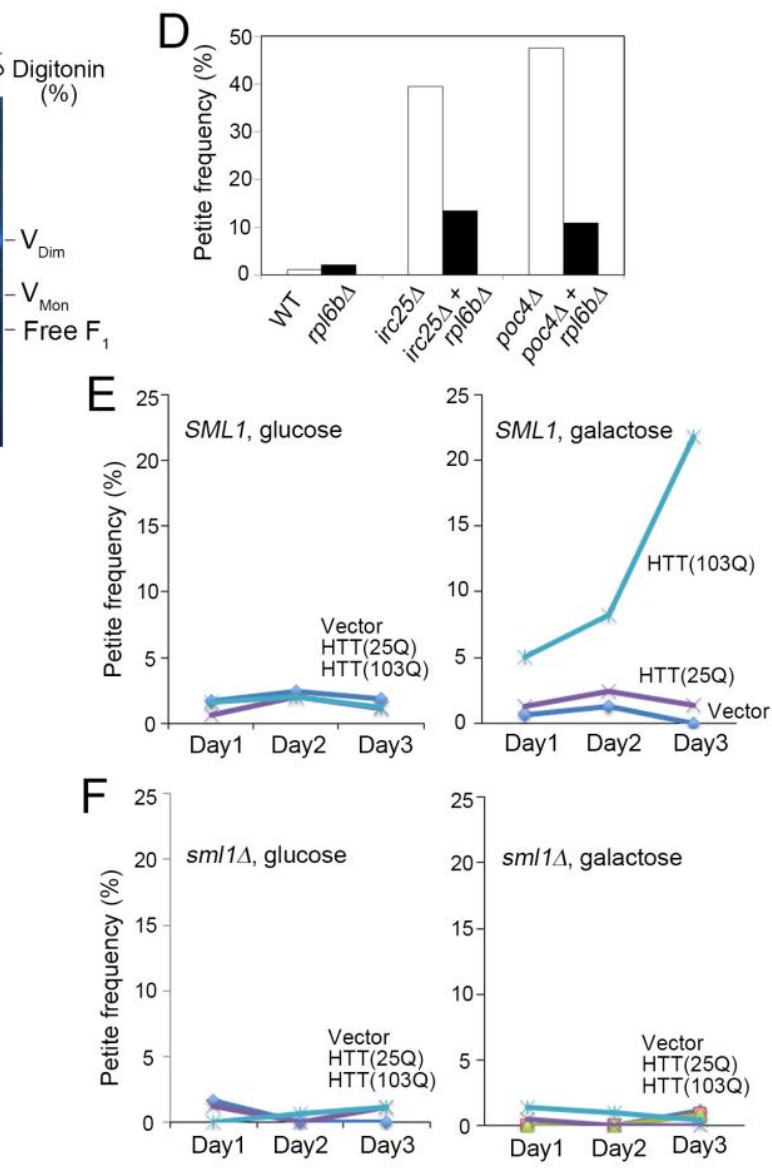

Figure 2. Global proteostatic stress affects mtDNA stability. (A) Respiratory growth on YPGly medium is moderately reduced in irc25 $\Delta$ and poc4 $\Delta$ mutants. (B) In-gel activity staining showing that the biogenesis of the monomeric $\left(\mathrm{V}_{\mathrm{Mon}}\right)$ and dimeric $\left(\mathrm{V}_{\text {Dim }}\right)$ forms of $\mathrm{F}_{1} \mathrm{~F}_{\mathrm{o}}$-ATP synthase is little affected in the irc $25 \Delta$ and poc4 $\Delta$ mutants. (C) Mitochondrial fragmentation in irc25 $\Delta$ and poc4 $\Delta$ mutants. (D) Petite production in the $\operatorname{irc} 25 \Delta$ and poc $4 \Delta$ mutants is suppressed by the disruption of RPL6B that reduces global protein synthesis. (E) Induction of petite colonies in wild-type yeast cells expressing human HTT(103Q) but not HTT(25Q). Transformants of plasmids expressing GAL10controlled HTT(103Q) and HTT(25Q) were grown in selective medium for 1-3 days as indicated before being plated onto YPD medium for scoring petite colonies. Disruption of SML1 suppresses petite production from HTT(103Q)-expressing cells. 

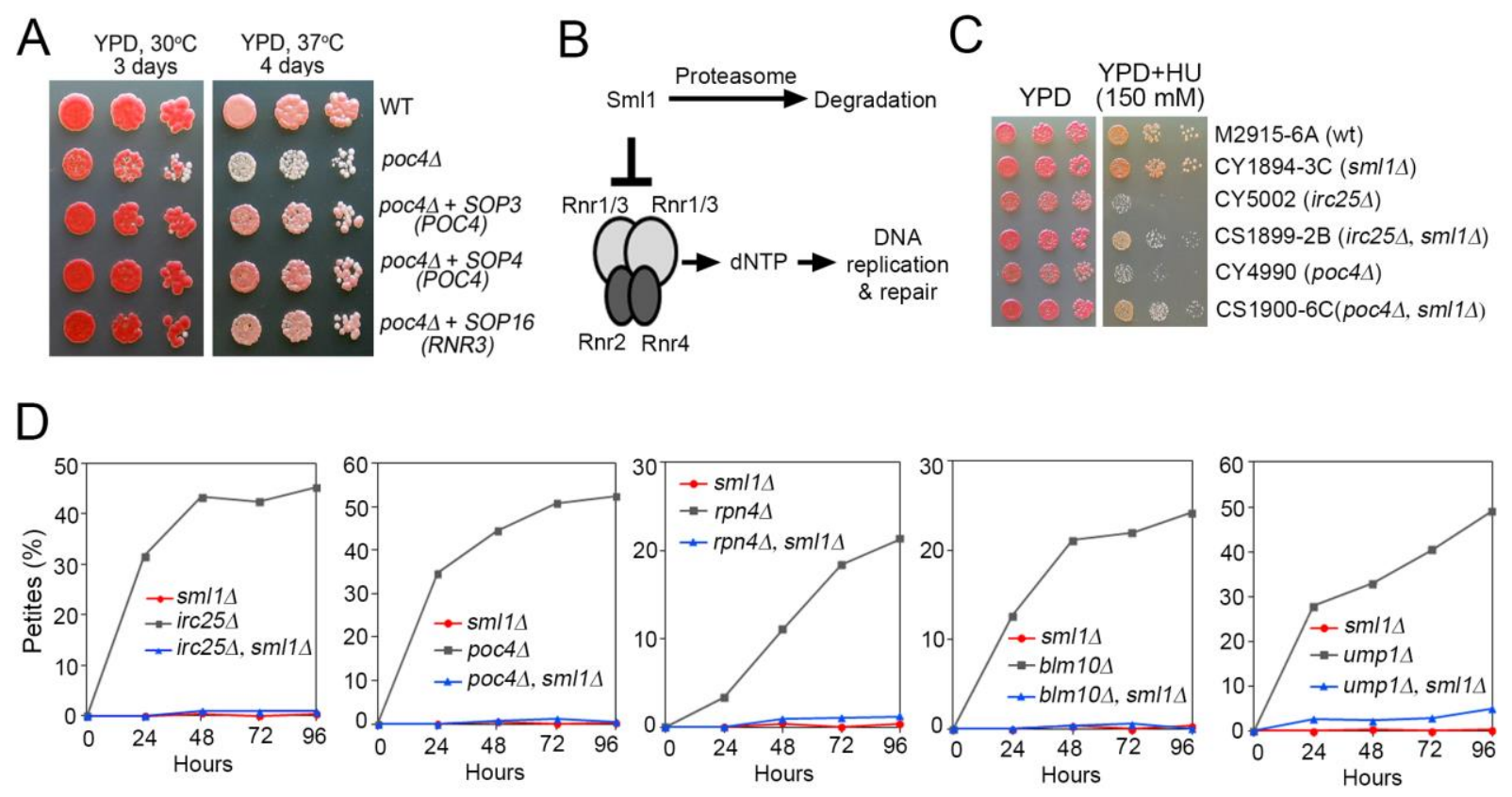

Figure 3

Figure 3. Genetic interaction between $20 \mathrm{~S}$ proteasome mutants and the RNR pathway. (A) Overexpression of $R N R 3$ suppresses the formation of white (petite) colonies in the poc $4 \Delta$ mutant on YPD medium. (B) Schematics depicting the inhibition of RNR by Sml1. (C) Sensitivity of irc25 $\Delta$ and poc4 $\Delta$ mutants to hydroxyurea, which is partially suppressed by the disruption of $S M L 1$. (D) Disruption of $S M L 1$ suppresses petite production from $20 \mathrm{~S}$ proteasome mutants. 


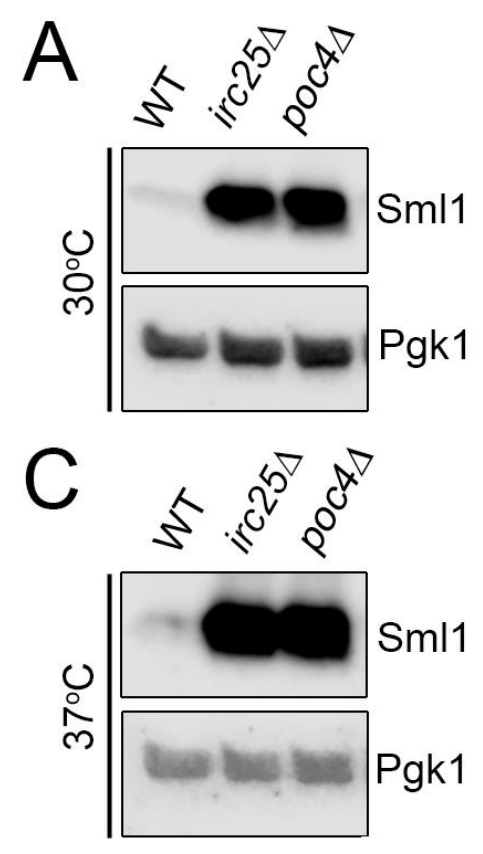

B

Figure 4

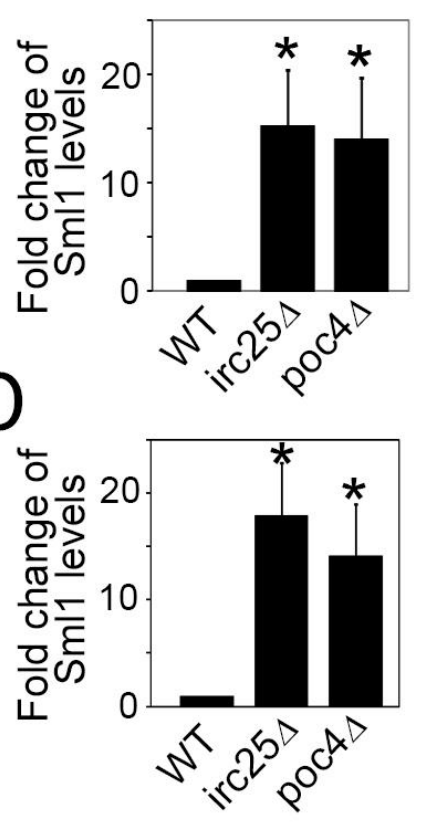

Figure 4. Stabilization of Sml1 in irc25 $\Delta$ and poc4 $\Delta$ mutants. (A) and (C) Western blot showing stabilization of Sml1 in $\operatorname{irc} 25 \Delta$ and poc4 $\Delta$ mutants grown at $30^{\circ} \mathrm{C}$ and $37^{\circ} \mathrm{C}$. (B) and (D), quantitation of (A) and (C) respectively. ${ }^{*}, p<0.05$. 

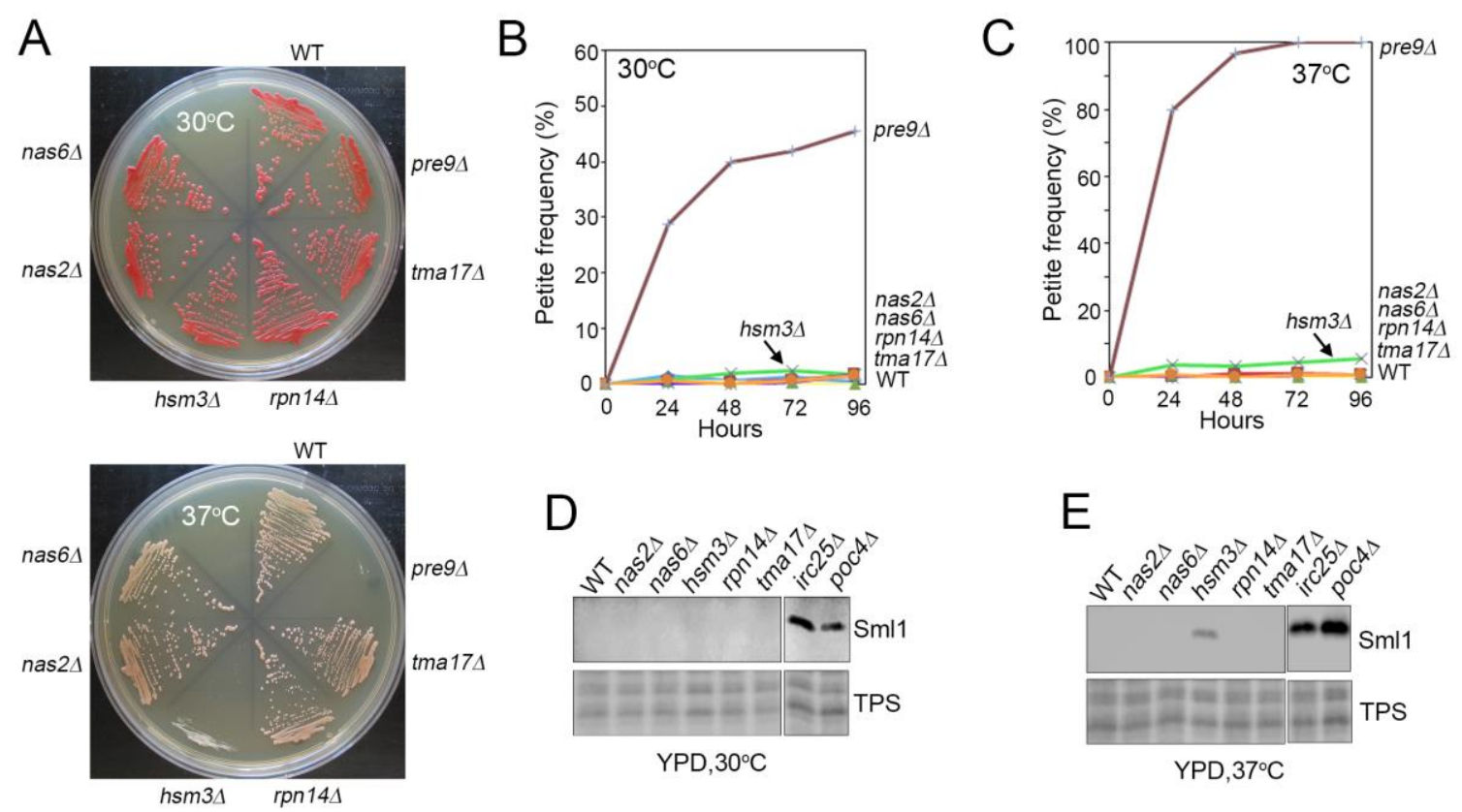

YPD, $37^{\circ} \mathrm{C}$

Figure 5

Figure 5. Effect of mutations in the 19S proteasome on mtDNA stability and Sml1 accumulation. (A) Growth of $19 \mathrm{~S}$ proteasome mutants on YPD medium at $30^{\circ} \mathrm{C}$ and $37^{\circ} \mathrm{C}$. (B) and (C) Petite frequency in $19 \mathrm{~S}$ proteasome mutants grown at $30^{\circ} \mathrm{C}$ and $37^{\circ} \mathrm{C}$ respectively. (D) and (E) Sml1 levels in $19 \mathrm{~S}$ proteasome mutants grown at $30^{\circ} \mathrm{C}$ and $37^{\circ} \mathrm{C}$ respectively. TPS, total protein staining. 

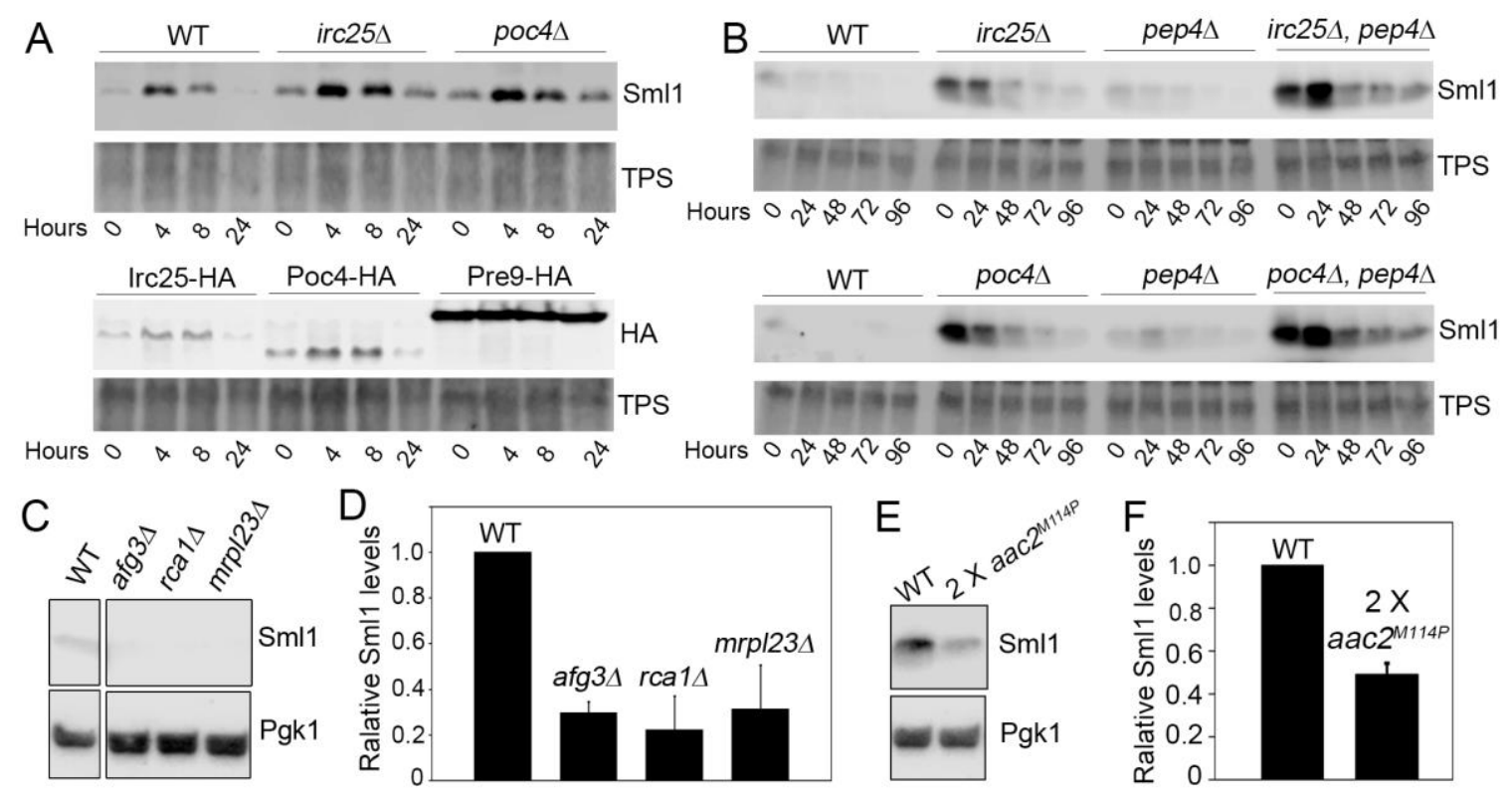

Figure 6

Figure 6. Sml1 levels at different metabolic states and in cells with destabilized mtDNA. (A) Accumulation of Sml1 (upper panel), Irc25-HA, Poc4-HA and Pre9-HA (lower panel) at different growth stages in YPD medium $\left(30^{\circ} \mathrm{C}\right)$. TPS, total protein staining. (B) Western blot showing that degradation of Sml1 in stationary phase is dependent of $20 \mathrm{~S}$ proteasome and vacuolar function. Cells were gown in YPD $30^{\circ} \mathrm{C}$ for 24, 48, 72 and 96 hours without refreshing medium. (C) Western blot showing reduced Sml1 accumulation in afg3 $\Delta, r c a l \Delta$ and mrpl23 $\Delta$ mutants. (D) Quantitation of (C). (E) Western blot showing reduced Smll accumulation in cells expressing 2 chromosomally integrated $a a c 2^{M 114 P}$. (F) Quantitation of (E). 